\title{
Sociodemographic characteristics of patients and their use of post-bariatric contouring surgery in the US
}

Ibrahim Al-Sumaih ${ }^{1,2^{*}}$, Michael Donnelly ${ }^{1}$ and Ciaran $\mathrm{O}^{\prime} \mathrm{Neill}^{1}$

\begin{abstract}
Background: Expansion of healthcare insurance coverage to bariatric surgeries has led to an increased demand from patients for post-bariatric contouring surgeries. This study examined the relationship between the use of contouring procedures on post-bariatric surgery patients, clinical need and sociodemographic factors.

Methods: Data were extracted from the Healthcare Cost and Utilization Project (HCUP) Nationwide Ambulatory Surgery Sample (NASS) regarding hospital-owned ambulatory surgical centres in the US. Episodes without missing values relating to patients, 18 years old or above were the primary unit of analysis. Episodes were excluded if the field regarding expected payer was reported as "no charge."The primary outcome was the likelihood of panniculectomy, abdominoplasty, and mastopexy among post-bariatric surgery patients; and the degree to which uptake of these types of contouring surgery were associated with age, gender, median households' income, expected payer, patient's location, and comorbidity.
\end{abstract}

Results: A total of 66,368 weighted episodes of care received by patients who had had bariatric surgery were extracted (54,684 female [82.4\%]; mean age, 51.3 [SD, 12.1]; 6219 episodes had contouring surgeries [9.37\%]). Panniculectomy was the most common post-bariatric contouring procedure (3.68\%). Uptake of post-bariatric contouring procedures was associated with age, sex, payment type, area-based measures of median household income, and patient location. Compared to Medicare insured patients, the odds of receiving contouring surgery among self-payers were 1.82 (95\% Cl, 1.47 to 2.26) for panniculectomy, 14.79 (95\% Cl, 12.19 to 17.93) for abdominoplasty and 47.97 (95\% $\mathrm{Cl}, 32.76$ to 70.24$)$ for mastopexy. Rank order of comorbidity profiles also differed between insured and self-paying recipients of contouring surgery.

Conclusions: Insurance status of bariatric surgery patients and their sex were strongly associated with receipt of a range of contouring procedures. Self-payments were associated with a doubling of the odds of having panniculectomy and an increase in the odds to approximately 14 times for abdominoplasty and 48 times for mastopexy. Thus, access to contouring surgery by post-bariatric patients may be disproportionately dependent on personal preference supported by ability to pay rather than clinical need. Further research is needed to examine the impact of contouring or delayed/denied contouring on health status.

Keywords: Insurance coverage, Ambulatory surgical procedures, United States, Delivery of health care

*Correspondence: ialsumaih01@qub.ac.uk

${ }^{1}$ Centre for Public Health, School of Medicine, Dentistry and Biomedical Sciences, Institute of Clinical Sciences, Queen's University Belfast, Block B, Royal Victoria Hospital, Belfast, UK BT12 6BA, UK

Full list of author information is available at the end of the article

\section{Background}

Obesity is a global epidemic [1]. In the US, the prevalence of obesity had reached $38.5 \%$ in 2016 and is expected to affect $44 \%$ of the US population by 2031 [2]. The direct 
medical cost of obesity and obesity-related diseases was estimated at $\$ 98.1$ billion in the US in 2008 [3]. Numerous weight reduction interventions have been attempted to address the epidemic but bariatric surgery remains the most cost-effective and durable intervention at an individual level $[4,5]$. Bariatric surgery has become more prevalent in the US after insurance coverage expansion to include laparoscopic sleeve gastrectomy in 2011 [6]. Patients are expected to reach their lowest weight in the first year after bariatric surgery [7]. Health concerns as well as self-image have been posited as the main motivators among bariatric surgery candidates [8-10]. The rapid weight loss post-surgery, however, can lead to sagging skin in different parts of the body [11]. Patients commonly complain of sagging skin at the anterior abdomen and chest which can result in poor hygiene, recurrent infection, impaired: mobility; sexual relations; social interaction; quality of life and; negative self-image [11-14].

Contouring surgery may improve the post-bariatric patient's self-image, quality of life and help address conditions associated with the sagging skin [15]. It is also argued to play a role in maintaining body weight and prevent weight regain after bariatric surgery $[16,17]$. The rate of contouring surgeries among those who lost significant weight in the US grew by $10 \%$ from 2015 to 2016 [18]. In the US, more than two thirds of the postbariatric population desire to have contouring surgeries but cost remains a key barrier [19]. The American Society of Plastic Surgeons have recommended criteria for classification of contouring procedures into reconstructive and cosmetic procedures in order to encourage insurance expansion and enhance patients access to reconstructive procedures like panniculectomy and mastopexy [20,21]. The availability of ambulatory surgical centres has also facilitated increased patient access to most elective surgeries by lowering cost including abdominoplasty which is principally (48.8\%) performed in ambulatory surgical centers [22, 23].

There is a paucity of research examining the post-bariatric patient's access to, and use of, contouring procedures. Among the few studies in this area, one in New York State, US (a state which was considered to be flexible in terms of criteria for reimbursement) found that only $6 \%$ of post-bariatric patients had undergone contouring surgeries $[24,25]$. Another recent study on a smaller sample found that $12.7 \%$ of bariatric population underwent contouring surgery in the US [26]. Giladi et al. [27] investigated Medicaid expansion which included panniculectomy on New York patient's access to contouring surgery and found that an increasing number of Medicaid patients accessed panniculectomy but the upward utilisation trend by uninsured patients was not affected. The rising trend of uninsured bariatric patients presenting for contouring suggests a divergence between patients' wants and insurance company criteria based on clinical need. Studies have highlighted a disconnect between the opinions of Members of the American Society of Plastic Surgeons on the grounds for which access to contouring should be provided and the criteria used by insurance companies [25]. For example, conditions such as depression and anxiety, commonly found in the postbariatric population may not provide a basis upon which insurance coverage is offered [28,29].

Given the current paucity of research, this study (the first study of its type using nationally representative data from hospital-owned ambulatory surgical centres) investigated factors that may contribute to differences in uptake of contouring surgeries among post-bariatric surgery patients in the US.

\section{Methods}

\section{Data source}

The study data were drawn from 2016 discharge data from the Nationwide Ambulatory Surgery Sample (NASS), Healthcare Cost and Utilization Project (HCUP), Agency for Healthcare Research and Quality. The HCUP NASS data is the largest ambulatory care dataset in the US and includes 7,608,879 observations from $63 \%$ of hospital-owned ambulatory surgical facilities in the US [30]. The data included the age and gender as well as median household income for the ZIP code of the patient whose episode was captured in the data. Also included were details of the expected payer, total charge, the Current Procedural Terminology (CPT) codes for procedures performed, tenth revision of the International Classification of Diseases (ICD 10) codes for patient's diagnoses, and facility characteristics including bed size capacity, hospital location and teaching status at which services were provided.

\section{Population}

Data for episodes of care where bariatric surgery (ICD 10 code is Z9884) appeared on the list of co-morbidities were included in the study. Episodes that related to a person less than 18 years old or having a missing value among included variables were excluded. To avoid potential disclosure issues episodes where the expected payer was reported as "no charge" were also excluded (15 episodes). CPT codes for post-bariatric contouring procedures were adopted from the American Society of Plastic Surgeons guidelines for recording contouring procedures [31]. A full list of CPT codes of post-bariatric contouring procedures used in the study can be seen in (Additional file 1: Table A1). Forearm and submental skin excision were merged with excision of excessive skin in 
other areas in order to adhere to the HCUP guidelines for reporting observations of equal or less than 10 observations per cell [32]. For the purpose of exploring common medical history that bariatric population present with, a list of the common ICD 10 was generated for each of the popular contouring procedures. A full list of the ICD 10 codes used can be seen in (Additional file 1: Table A2).

\section{Statistical analysis}

Statistical analysis of the weighted and unweighted sample was presented as frequency and percentages for categorical variables as well as mean and standard deviation for continuous variables. Total charges were reported as medians and interquartile ranges because of the skewness (See Additional file 1: Table A3). The results of the weighted sample analyses are those presented. All results were weighted according to the recommendations by the HCUP [33]. Frequencies of the weighted variables were rounded. Logistic regression was used to estimate the odds ratios and $95 \%$ confidence intervals for covariates in regressions related to panniculectomy, abdominoplasty and mastopexy. In order to examine variance in possession of insurance and common medical necessity, analyses also compared uptake based on insurance status using chi square tests. Statistical significance was defined at $p$ value $<.05$. All analyses were undertaken in Stata version 15 (StataCorp LLC College Station, TX).

\section{Results}

A total of 66,368 episodes of post-bariatric patients were extracted. The majority of the sample was female (82.40\%), and the mean age was approximately 51 years old. More than half of the bariatric sample held private insurance $(37,561 ; 56.60 \%)$ and a minority were selfpayers $(2359 ; 2.89 \%)$. The contouring procedure was performed on approximately one tenth of the post-bariatric sample (9.37\%). Panniculectomy (3.68\%) and abdominoplasty $(3.51 \%)$ were the most common contouring procedures among the bariatric population followed by mastopexy (1.16\%). Detailed descriptive statistics of the sample are presented in Tables 1 and 2. Median total charges of mastopexy, panniculectomy, and abdominoplasty were $27,130,25,178$, and 24,656 US dollar, respectively (See Additional file 1: Table A1).

The results of logistic regression analysis are shown in Table 3. As can be seen, episodes related to younger and female post-bariatric patients were more likely to have contouring surgeries. Compared to the lowest median household income ZIP code, the highest income zip code dwellers was associated with decreased odds of having panniculectomy (odds ratio [OR], 0.76 [95\% CI, 0.65 to 0.89] p .001) and abdominoplasty (OR, 0.78 [95\% CI, 0.67 to 0.91 ] p .002) and increased odds of having mastopexy
(OR, 1.44 [95\% CI, 1.08 to 1.91] p .013). Compared to Medicare, episodes involving self-payers were associated with higher odds of having panniculectomy (OR, 1.82 [95\% CI, 1.47 to 2.26] $p<0.001$ ), abdominoplasty (OR, 14.78 [95\% CI, 12.19 to 17.93 ] $p<0.001$ ), and mastopexy (OR, 47.97 [95\% CI, 32.76 to 70.23] $p<0.001$ ). Patients' geographic locations were also found to be associated with uptake of contouring surgeries with lower odds for episodes involving patients from less densely populated areas compared to more densely populated areas.

In Tables 4, 5, and 6 common diagnoses among those in receipt of panniculectomy, abdominoplasty, and mastopexy are shown together with insurance status. As can be seen, different patterns are evident in term of the rank ordering of conditions and the insurance status of those receipt of contouring surgery. While self-pay comprised roughly $10 \%$ of panniculectomy episodes, it made up over $50 \%$ in mastopexy episodes. Similarly, while there is evident similarity in the comorbidities recorded, the rank ordering of these differs markedly.

\section{Discussion}

Sagging skin is a common unwanted outcome of bariatric surgeries that can also give rise to health issues. A majority of the post-bariatric population want surgical contouring but many lack access to their preferred type of surgeries due to high out of pocket costs [34]. The current study estimated that of all inpatient episodes among patients who had previously had bariatric surgery just over 9\% were for at least one contouring surgery in 2016. Some caution is warranted in the interpretation of this statistic. As noted, we examine here episodes of care not patients - a small number of patients may have received more than one procedure separately in the same year. Also, we examine episodes of care in 1 year only, i.e. the incidence of contouring not the prevalence, if a patient had received contouring prior to 2016 related to previous bariatric surgery this would not be captured in our data. This said, as noted most contouring takes place within a year of surgery and our estimate of incidence falls within the range of previous estimates of prevalence over a long term period in the US [24, 26] and of prevalence in a recent Dutch study again over a longer time period $(9.13 \%)$ [17]. We can think of no reason why incident contouring in 2016 would exhibit a different distribution with respect to any of the variables used to explain uptake in 2016 compared to prevalence. Our findings in respect of the relationship with uptake, therefore, remain robust.

The common contouring procedures found in our study were the excision of excess skin in the abdominal area either by panniculectomy or abdominoplasty which account for $7.19 \%$ of the total post-bariatric episodes. A 
Table 1 Descriptive statistics of the sample

\begin{tabular}{|c|c|c|}
\hline Variable & Unweighted $(n=48,263)$ & Weighted $(n=66,368)$ \\
\hline Female, No. (\%) & $39,739(82.34)$ & $54,684(82.40)$ \\
\hline Age, mean (SD), years & $51.29(12.11)$ & $51.30(12.12)$ \\
\hline \multicolumn{3}{|l|}{ Expected payer, No. (\%) } \\
\hline Medicare & $11,960(24.78)$ & $16,345(24.63)$ \\
\hline Medicaid & $5544(11.49)$ & $7520(11.33)$ \\
\hline Private & $27,182(56.32)$ & $37,561(56.60)$ \\
\hline Self-pay & $1685(3.49)$ & $2359(3.55)$ \\
\hline Other & $1892(3.92)$ & $2582(3.89)$ \\
\hline \multicolumn{3}{|l|}{ Income, No. (\%) } \\
\hline Highest income quartile & $10,556(21.96)$ & $14,642(22.06)$ \\
\hline Second highest income quartile & $13,468(27.91)$ & $18,422(27.76)$ \\
\hline Second lowest income quartile & $13,160(27.27)$ & $18,028(27.16)$ \\
\hline Lowest income quartile & $11,079(22.96)$ & $15,275(23.02)$ \\
\hline \multicolumn{3}{|l|}{ Patient location, No. (\%) } \\
\hline Central counties of more than 1 million population & $12,870(26.67)$ & $17,525(26.41)$ \\
\hline Fringe counties of more than 1 million population & $12,266(25.41)$ & $16,850(25.39)$ \\
\hline Metropolitan of less than 1 million population & $11,033(22.86)$ & $15,193(22.89)$ \\
\hline Metropolitan of less than 250,000 population & $4451(9.22)$ & $5960(8.98)$ \\
\hline Micropolitan & $4721(9.78)$ & $6705(10.10)$ \\
\hline Other & $2922(6.05)$ & $4134(6.23)$ \\
\hline Urban hospital, No. (\%) & $44,598(92.41)$ & $60,719(91.49)$ \\
\hline Teaching hospital, No. (\%) & $34,293(71.05)$ & $45,639(68.77)$ \\
\hline \multicolumn{3}{|l|}{ Hospital bed size capacity, №. (\%) } \\
\hline $300+$ & $26,974(55.89)$ & $35,608(53.65)$ \\
\hline $100-299$ & $17,089(35.41)$ & $23,763(35.81)$ \\
\hline$<100$ & $4200(8.70)$ & $6996(10.54)$ \\
\hline Contouring procedure, No. (\%) & $4604(9.54)$ & $6219(9.37)$ \\
\hline Panniculectomy & $1802(3.73)$ & $2443(3.68)$ \\
\hline Abdominoplasty & $1739(3.60)$ & $2327(3.51)$ \\
\hline Modified abdominoplasty & $165(0.34)$ & $229(0.34)$ \\
\hline Excision of thigh skin & $296(0.61)$ & $400(0.60)$ \\
\hline Excision of leg skin & $26(0.05)$ & $32(0.05)$ \\
\hline Excision of hip skin & $47(0.10)$ & $63(0.10)$ \\
\hline Excision of buttock skin & $78(0.16)$ & $105(0.16)$ \\
\hline Excision of arm skin & $484(1.00)$ & $653(0.98)$ \\
\hline Excision of skin in other area & $215(0.45)$ & $289(0.44)$ \\
\hline Mastopexy & $559(1.16)$ & $773(1.16)$ \\
\hline Mastectomy for gynecomastia & $31(0.06)$ & $42(0.06)$ \\
\hline
\end{tabular}

Frequency of weighted variables are rounded

previous longitudinal study by Altieri et al. (2017) had examined 37,806 patients underwent bariatric surgeries between 2004 and 2010 in the New York state and found that only $5.58 \%$ of the bariatric population had underwent abdominal contouring surgeries within 4 years of having the bariatric surgery [24]. It seems possible that the higher rate of abdominal contouring surgeries found in our study is due to the steady increasing trend of body contouring between 2013 and 2016 by 31\% as estimated by the American Society of Plastic Surgeons [18, 35]. Another explanation could be related to the differences in the study design, as Altieri study was confined the length of time since bariatric surgeries to 4 years where in our study participants could had either bariatric or bariatric surgeries at any time in the past.

Among all the socioeconomic variables examined in the logistic regression models, the expectation of selfpay is notable as is being a female. The odds for having 
Table 2 Detailed descriptive statistics by type of surgery

\begin{tabular}{|c|c|c|c|c|c|}
\hline Variable & Panniculectomy & Abdominoplasty & Mastopexy & $\begin{array}{l}\text { Other types } \\
\text { of contouring } \\
\text { surgeries }\end{array}$ & None \\
\hline Female, No. (\%) & $2116(86.63)$ & $2074(89.11)$ & Males are less than 10 & $1364(90.29)$ & $49,149(81.71)$ \\
\hline Age, mean (SD), years & $47.84(11.63)$ & $45.78(10.96)$ & $45.76(10.87)$ & $47.92(11.32)$ & $51.73(12.12)$ \\
\hline \multicolumn{6}{|l|}{ Expected payer, No. (\%) } \\
\hline Medicare & $598(24.48)$ & $266(11.45)$ & $48(6.22)$ & $137(9.05)$ & $15,354(25.53)$ \\
\hline Medicaid & $448(18.33)$ & $390(16.77)$ & $57(7.43)$ & $189(12.53)$ & $6508(10.82)$ \\
\hline Private & $1107(45.32)$ & $955(41.04)$ & $206(26.66)$ & $451(29.84)$ & $35,075(58.31)$ \\
\hline Self-pay & $200(8.18)$ & $631(27.13)$ & $428(55.39)$ & $653(43.25)$ & $875(1.45)$ \\
\hline Other & $90(3.68)$ & $84(3.61)$ & $33(4.3)$ & $81(5.33)$ & $2336(3.88)$ \\
\hline \multicolumn{6}{|l|}{ Income, No. (\%) } \\
\hline Highest income quartile & $451(18.47)$ & $558(23.98)$ & $247(31.98)$ & $423(28.03)$ & $13,221(21.98)$ \\
\hline Second highest income quartile & $668(27.33)$ & $622(26.73)$ & $217(28.13)$ & $427(28.30)$ & $16,706(27.77)$ \\
\hline Second lowest income quartile & $683(27.94)$ & $547(23.52)$ & $172(22.27)$ & $355(23.47)$ & $16,477(27.39)$ \\
\hline Lowest income quartile & $642(26.26)$ & $600(25.77)$ & $136(17.63)$ & $305(20.20)$ & $13,744(22.85)$ \\
\hline \multicolumn{6}{|l|}{ Patient location, No. (\%) } \\
\hline $\begin{array}{l}\text { Central counties of more than } 1 \text { million popula- } \\
\text { tion }\end{array}$ & $748(30.62)$ & $748(32.13)$ & $249(32.28)$ & $489(32.38)$ & $15,534(25.83)$ \\
\hline $\begin{array}{l}\text { Fringe counties of more than } 1 \text { million popula- } \\
\text { tion }\end{array}$ & $570(23.34)$ & $666(28.62)$ & $236(30.55)$ & $479(31.73)$ & $15,163(25.21)$ \\
\hline Metropolitan of less than 1 million population & $582(23.81)$ & $479(20.59)$ & $149(19.25)$ & $295(19.55)$ & $13,849(23.03)$ \\
\hline Metropolitan of less than 250,000 population & $188(7.69)$ & $176(7.54)$ & $63(8.20)$ & $97(6.44)$ & $5508(9.16)$ \\
\hline Micropolitan & $204(8.36)$ & $156(6.72)$ & $43(5.61)$ & $72(4.75)$ & $6275(10.43)$ \\
\hline Other & $151(6.18)$ & $102(4.39)$ & $31(4.12)$ & $78(5.14)$ & $3820(6.35)$ \\
\hline Urban hospital, No. (\%) & $2335(95.58)$ & $2249(96.62)$ & $758(98.06)$ & $1473(97.50)$ & $54,713(90.96)$ \\
\hline Teaching hospital, No. (\%) & $1951(79.85)$ & $1772(76.15)$ & $597(77.33)$ & 1198 (79.32) & $40,772(67.79)$ \\
\hline \multicolumn{6}{|l|}{ Hospital bed size capacity, №. (\%) } \\
\hline $300+$ & $1612(66.00)$ & $1406(60.42)$ & $464(60.08)$ & $944(62.49)$ & $31,701(52.70)$ \\
\hline $100-299$ & $648(26.52)$ & $744(31.97)$ & $246(31.79)$ & $478(31.63)$ & $21,900(36.41)$ \\
\hline$<100$ & $183(7.48)$ & $177(7.61)$ & $63(8.14)$ & $89(5.88)$ & $6548(10.89)$ \\
\hline
\end{tabular}

Frequency of weighted variables are rounded

contouring procedures among self-payers' episodes compared to Medicare are 1.82 and 14.79 for panniculectomy and abdominoplasty, respectively. Differences in the odds for different procedures may reflect healthcare insurers' positions towards contouring surgeries. Recent literature has examined healthcare insurers policies including Medicare and Medicaid toward contouring surgeries coverage. While $98 \%$ of healthcare insurers grant cover under certain circumstances for panniculectomy, only $29 \%$ of the insurers cover abdominoplasty [36]. The low rate of abdominoplasty coverage may explain the higher odds of self-pay as the only alternative means of accessing the procedure. This is consistent with a perception of the procedure being viewed as elective in nature and difficult to insure given the potential for moral hazard.

The uptake of contouring surgeries is more evident among females as expected. Data from the American Society for Aesthetic Plastic Surgery shows that more than $90 \%$ of the cosmetic surgical procedures in 2016 were performed on women [37]. High consumption of abdominal contouring procedure was also established in Altieri [24]. Females were also known to have a higher rate of consumption of bariatric surgeries. In a crosssectional study on Medicare data, out of 77,774 bariatric surgeries between 2014 and 2016, approximately $74 \%$ were performed on females [38].

Insurance coverage for mastopexy is even less common. It has been reported that just $23 \%$ of insurers provide coverage for post-bariatric mastopexy including Medicaid [39]. This low level of coverage likely explains the higher dependence on self-pay as a source of funding for this procedure and as with others is likely grounded in its perceived elective nature and the perceived potential for moral hazard by insurers.

Another interesting finding is the pattern of comorbidities between insured and self-payers episodes. The 
Table 3 Logistic regression models of common contouring surgeries as outcomes of socioeconomic characteristics

\begin{tabular}{|c|c|c|c|}
\hline Variable & Panniculectomy & Abdominoplasty & Mastopexy \\
\hline \multicolumn{4}{|l|}{ Age } \\
\hline $18-35$ & Ref & Ref & Ref \\
\hline $36-45$, OR $(95 \% \mathrm{Cl})$ & 0.83 (0.71 to 0.96$)$ & 0.80 (0.69 to 0.93$)$ & 0.85 (0.66 to 1.11$)$ \\
\hline$P$ value & .016 & .005 & .246 \\
\hline $46-55$, OR (95\% Cl) & 0.75 (0.64 to 0.87 ) & 0.67 (0.57 to 0.78$)$ & 0.64 (0.49 to 0.85$)$ \\
\hline$P$ value & $<.001$ & $<.001$ & .002 \\
\hline $56+, \mathrm{OR}(95 \% \mathrm{Cl})$ & 0.47 (0.39 to 0.56$)$ & 0.38 (0.32 to 0.45$)$ & 0.48 (0.36 to 0.65$)$ \\
\hline$P$ value & $<.001$ & $<.001$ & $<.001$ \\
\hline Female, OR (95\% Cl) & 1.24 (1.08 to 1.43$)$ & $1.36(1.16$ to 1.59$)$ & 14.96 (6.67 to 33.59) \\
\hline$P$ value & .003 & $<.001$ & $<.001$ \\
\hline \multicolumn{4}{|l|}{ Median household income } \\
\hline Lowest income & Ref & Ref & Ref \\
\hline Second lowest income, OR (95\% Cl) & 0.96 (0.84 to 1.09$)$ & 0.77 (0.67 to 0.89$)$ & 1.05 (0.79 to 1.39$)$ \\
\hline$P$ value & .515 & $<.001$ & .750 \\
\hline Second highest income, OR (95\% Cl) & 0.91 (0.79 to 1.04$)$ & 0.80 (0.69 to 0.93 ) & $1.22(0.93$ to 1.61$)$ \\
\hline$P$ value & .178 & .002 & .158 \\
\hline Highest income, OR (95\% Cl) & 0.76 (0.65 to 0.89$)$ & 0.78 (0.67 to 0.91$)$ & 1.44 (1.08 to 1.91$)$ \\
\hline$P$ value & .001 & .002 & .013 \\
\hline \multicolumn{4}{|l|}{ Expected payer } \\
\hline Medicare & Ref & Ref & Ref \\
\hline Medicaid, OR (95\% Cl) & 1.10 (0.93 to 1.30$)$ & 1.94 (1.58 to 2.37$)$ & $1.62(1.01$ to 2.59$)$ \\
\hline$P$ value & .277 & $<.001$ & .045 \\
\hline Private, OR (95\% Cl) & 0.62 (0.54 to 0.71$)$ & 1.11 (0.93 to 1.32$)$ & 1.32 (0.89 to 1.96$)$ \\
\hline$P$ value & $<.001$ & .245 & .171 \\
\hline Self-pay, OR (95\% Cl) & 1.82 (1.47 to 2.26$)$ & 14.78 (12.19 to 17.93$)$ & 47.97 (32.76 to 70.23$)$ \\
\hline$P$ value & $<.001$ & $<.001$ & $<.001$ \\
\hline Other, OR (95\% Cl) & 0.77 (0.58 to 1.01$)$ & 1.51 (1.13 to 2.03$)$ & $3.36(1.99$ to 5.66$)$ \\
\hline$P$ value & .055 & .006 & $<.001$ \\
\hline \multicolumn{4}{|l|}{ Patient location } \\
\hline Central, OR (95\% Cl) & Ref & Ref & Ref \\
\hline Fringe $>1 \mathrm{mln}, \mathrm{OR}(95 \% \mathrm{Cl})$ & 0.83 (0.73 to 0.96$)$ & 0.92 (0.81 to 1.05$)$ & 0.79 (0.63 to 1.001$)$ \\
\hline$P$ value & .009 & .219 & .051 \\
\hline $250 \mathrm{~K}-1 \mathrm{mln}, \mathrm{OR}(95 \% \mathrm{Cl})$ & 0.88 (0.77 to 1.00$)$ & 0.78 (0.67 to 0.90$)$ & 0.80 (0.62 to 1.04$)$ \\
\hline$P$ value & .049 & .001 & .098 \\
\hline $50 \mathrm{~K}-250 \mathrm{~K}, \mathrm{OR}(95 \% \mathrm{Cl})$ & 0.71 (0.58 to 0.85$)$ & 0.71 (0.58 to 0.87 ) & 0.82 (0.59 to 1.16$)$ \\
\hline$P$ value & $<.001$ & .001 & .267 \\
\hline Micropolitan, OR (95\% Cl) & 0.67 (0.55 to 0.81$)$ & 0.58 (0.47 to 0.72 ) & 0.62 (0.42 to 0.93 ) \\
\hline$P$ value & $<.001$ & $<.001$ & .019 \\
\hline Other, OR (95\% Cl) & 0.78 (0.63 to 0.97 ) & 0.56 (0.43 to 0.72 ) & 0.63 (0.40 to 1.00$)$ \\
\hline$P$ value & 0.026 & $<.001$ & .048 \\
\hline
\end{tabular}

majority of the healthcare insurers provide coverage against certain criteria particularly for panniculectomy and abdominoplasty [36]. The eligibility criteria vary across insurers [25]. In the case of panniculectomy, the commonly presented eligibility criterion is maceration of skin or skin infection not relived by topical or oral medication [25], which would explain the low number (below 10) of erythema intertrigo and panniculitis among self-payers.

Abdominoplasty episodes, on the other hand, are less adherent to the panniculectomy eligibility criteria related to comorbidities. Although it is covered by one-third of insurance companies, most of the insurers would cover abdominoplasty if the patients 
Table 4 Common diagnosis appeared with panniculectomy episodes

\begin{tabular}{lllll}
\hline Diagnosis & Overall $(\boldsymbol{n}=\mathbf{2 4 4 3})$ & Insured $(\boldsymbol{n}=\mathbf{2 2 4 3})$ & Self-payer $(\boldsymbol{n}=\mathbf{2 0 0})$ & $\boldsymbol{P}$ value \\
\hline Pannus, No. (\%) & $1528(62.53)$ & $1461(65.11)$ & $67(33.60)$ & $57(28.27)$ \\
Hypertension, No. (\%) & $884(36.20)$ & $828(36.20)$ & Small number & .0427 \\
Panniculitis, No. (\%) & $572(23.41)$ & $511(22.78)$ & $23(11.27)$ & $<.001$ \\
GERD, No. (\%) & $534(21.84)$ & & Small number \\
Erythema Intertrigo, No. (\%) & $451(18.46)$ & $412(18.35)$ & $32(15.76)$ & .0020 \\
Nicotine dependence, No. (\%) & $443(18.14)$ & $396(17.67)$ & $25(12.60)$ & .001 \\
Type 2 Diabetes, No. (\%) & $422(17.25)$ & $369(16.45)$ & $26(12.81))$ & .001 \\
Long term medication, No. (\%) & $395(16.15)$ & $323(14.42)$ & $21(10.33)$ & .2852 \\
Obesity, No. (\%) & $344(14.08)$ & $303(13.52)$ & $13(6.45)$ & .1987 \\
Depression, No. (\%) & $316(12.94)$ & & & .0210 \\
\hline
\end{tabular}

Table 5 Common diagnosis appeared with abdominoplasty episodes

\begin{tabular}{lllll}
\hline Diagnosis & Overall $(\boldsymbol{n}=\mathbf{2 3 2 7})$ & Insured $(\boldsymbol{n}=\mathbf{1 6 9 6})$ & Self-payer $(\boldsymbol{n}=\mathbf{6 3 1})$ & $\boldsymbol{P}$ value \\
\hline Pannus, No. (\%) & $1392(59.81)$ & $1098(64.73)$ & $294(46.60)$ & $125(19.84)$ \\
Hypertension, No. (\%) & $650(27.92)$ & $525(30.93)$ & $189(29.88)$ & $<.001$ \\
Lipodystrophy, No. (\%) & $482(20.69)$ & $293(17.27)$ & $101(16.01)$ & $<.001$ \\
GERD, No. (\%) & $448(19.25)$ & $347(20.46)$ & $248(39.34)$ & $30(4.69)$ \\
Cosmetic, No. (\%) & $405(17.42)$ & $157(9.26)$ & $78(12.40)$ & .0428 \\
Erythema Intertrigo, No. (\%) & $358(15.38)$ & $328(19.36)$ & $26(4.09)$ & $<.001$ \\
Nicotine dependence, No. (\%) & $356(15.32)$ & $278(16.40)$ & $84(13.28)$ & .001 \\
Panniculitis, No. (\%) & $326(14.02)$ & $300(17.72)$ & $40(6.31)$ & .001 \\
Long term medication, No. (\%) & $283(12.16)$ & $199(11.74)$ & $235(13.84)$ & \\
Obesity, No. (\%) & $275(11.80)$ & & .001 \\
\hline
\end{tabular}

Table 6 Common diagnosis appeared with mastopexy episodes

\begin{tabular}{lllll}
\hline Diagnosis & Overall $(\boldsymbol{n}=\mathbf{7 7 3})$ & Insured (345) & Self-payer (428) & $\boldsymbol{P}$ value \\
\hline Breast ptosis, No. (\%) & $558(72.22)$ & $227(65.80)$ & $331(77.39)$ & $189(44.17)$ \\
Cosmetic, No. (\%) & $251(32.50)$ & $62(18.02)$ & $71(16.55)$ & .0030 \\
Hypertension, No. (\%) & $177(22.97)$ & $107(30.95)$ & $96(22.38)$ & .0001 \\
Lipodystrophy, No. (\%) & $151(19.51)$ & $55(15.95)$ & $68(15.79)$ & .0001 \\
Long term medication, No. (\%) & $132(17.09)$ & $64(18.71)$ & $62(14.52)$ & .3789 \\
Pannus, No. (\%) & $132(17.04)$ & $69(20.16)$ & $57(13.39)$ & .0784 \\
GERD, No. (\%) & $118(15.32)$ & $51(17.71)$ & $51(11.93)$ & .1694 \\
Nicotine dependence, No. (\%) & $107(13.90)$ & $25(7.36)$ & $76(17.72)$ & .1430 \\
Abnormal weight loss, No. (\%) & $101(13.10)$ & $29(8.55)$ & $66(15.41)$ & .0005 \\
Breast hypoplasia, No. (\%) & $95(12.35)$ & & & .0148 \\
\hline
\end{tabular}

have diastasis recti. Examining the top common conditions associated with abdominoplasty, however, did not show diastasis recti as only 132 have diastasis recti of which $40 \%$ are self-payers. Although the presence of panniculectomy eligibility criteria such as intertrigo and panniculitis have diminished when examining the abdominoplasty episodes, a significant higher proportion of insured candidates have opted to choose abdominoplasty indicated that eligibility for panniculectomy was not limited to intertrigo and panniculitis. Ngaage et al. (2020) have recently examined insurance coverage policies and found that 
criteria for panniculectomy reimbursement was not limited to comorbidities but also include complaining of impaired mobility, having a minimum duration since bariatric surgery, a significant weight reduction achieved and maintained [36].

Breast ptosis followed by encounter for cosmetic reasons are the most common ICD 10 diagnosis codes for mastopexy episodes. The lack of insurance coverage for mastopexy in post-bariatric population is associated with a significantly higher prevalence of breast ptosis and cosmetic reasons among self-payers compared to insured. Only three private insurance companies have developed eligibility criteria for mastopexy [39]. The criteria include functional impairment, photographed breast ptosis, skin infection, and psychiatric assessment.

Our study has a number of limitations. First, it is based on cross-sectional data which allow us only to look at associations and not draw causal inferences. While this is a limitation imposed on us by the data, it still allows us to describe the activity and the nature of relations in an understudied area. Second, we are limited by the variables available to us to shed light on what may be interesting relationships. We cannot, for example, describe the interval between receipt of bariatric surgery and subsequent contouring surgery.

Similarly, as contouring is an elective procedure, customer choice may have been affected by many variables including surgeon reputation and in-network and out-of-network status as well as common criteria for reimbursement such as weight maintenance duration were not measured in the data.

Another missing variable that might have an impact on the overall rate of contouring surgeries is the history of previously performed contouring surgeries.

Again, these are limitations imposed on us by the data but our results help identify as avenues for further research.

Third, HCUP relates to observed episodes of care, rather than patients per se. It is, therefore, possible that two or more episodes belong to the same patient which could result in some overestimation of the number of procedures and of the degree of difference between some groups. It seems unlikely that instances of multiple procedures in a given year though would materially affect our findings.

Fourth, our data are drawn solely from the US and the findings may not be readily extrapolated to other countries. It is therefore important that these issues including experiences in other countries are addressed in further research.

\section{Conclusion}

Uptake of contouring appears to be significantly related to non-clinical factors such as insurance status and sex. Self-payment is the predominant payment method among those who underwent post-bariatric contouring surgeries indicating potential issues with the operation of insurance in this area that warrant further investigation.

\section{Abbreviations}

HCUP: Healthcare Cost and Utilization Project; NASS: Nationwide Ambulatory Surgery Sample; CPT: Current Procedural Terminology; ICD 10: Tenth revision of the International Classification of Diseases.

\section{Supplementary Information}

The online version contains supplementary material available at https://doi. org/10.1186/s12913-022-07692-1.

Additional file 1: Table A1. CPT codes for contouring surgeries.

Table A2. ICD 10 codes. Table A3. Total charge for solo procedure in US dollar.

\section{Acknowledgements}

The authors would like to acknowledge the Healthcare Cost and Utilization Project (HCUP) for providing access to the data used in this study.

\section{Authors' contributions}

IA and CON contributed to the conception and design of the study. CON contributed to the data acquisition. IA, MD, and CON contributed the data analysis and interpretation. IA and CON contributed to the manuscript drafting. CON and MD contributed to the editing of final manuscript and supervision. All authors have read and approved the manuscript.

\section{Funding}

Not applicable.

\section{Availability of data and materials}

The dataset supporting the conclusions of this article have been obtained from the Healthcare Cost and Utilization Project (HCUP). This dataset is publicly available with restrictions and can be ordered using the following link: https://www.distributor.hcup-us.ahrq.gov/.

\section{Declarations}

Ethics approval and consent to participate

Ethical approval was not required as the dataset anonymized by the Healthcare Cost and Utilization Project (HCUP) prior to receipt. The methods in this study were carried out in accordance with the relevant guidelines and regulations. All those involved in statistical analysis have completed the HCUP Data Usage Agreement online training.

\section{Consent for publication}

Not applicable.

\section{Competing interests}

The authors declare that they have no competing interests. Professor Michael Donnelly is a Senior Editorial Member for the BMC Health services research journal, and he had no role in handling of this manuscript.

\section{Author details}

${ }^{1}$ Centre for Public Health, School of Medicine, Dentistry and Biomedical Sciences, Institute of Clinical Sciences, Queen's University Belfast, Block B, Royal Victoria Hospital, Belfast, UK BT12 6BA, UK. ${ }^{2}$ Ministry of Health, Riyadh, Saudi Arabia. 
Received: 5 July 2021 Accepted: 17 February 2022

Published online: 07 March 2022

\section{References}

1. Health effects of overweight and obesity in 195 countries over 25 years. N Engl J Med. 2017;377(1):13-27. Available from: https://www-nejm-org. queens.ezp1.qub.ac.uk/doi/10.1056/NEJMoa1614362. Cited 2020 Dec 29.

2. Janssen F, Bardoutsos A, Vidra N. Obesity prevalence in the longterm future in 18 European countries and in the USA. Obes Facts. 2020;13(5):514-27 Available from: https://www.ncbi.nlm.nih.gov/pmc/ articles/PMC7670332/?report=abstract. Cited 2020 Dec 29.

3. Tsai AG, Williamson DF, Glick HA. Direct medical cost of overweight and obesity in the USA: a quantitative systematic review. Obes Rev. 2011;12:50-61 Available from: https://pubmed.ncbi.nlm.nih.gov/20059 703/. Cited 2020 Dec 29.

4. Acosta A, Streett S, Kroh MD, Cheskin LJ, Saunders KH, Kurian M, et al. White paper AGA: POWER — practice guide on obesity and weight management, education, and resources. Clin Gastroenterol Hepatol. 2017;15:631-649.e10 W.B. Saunders.

5. McGlone ER, Carey I, Veličković V, Chana P, Mahawar K, Batterham RL, et al. Bariatric surgery for patients with type 2 diabetes mellitus requiring insulin: clinical outcome and cost-effectiveness analyses. Ma RCW, editor. PLoS Med. 2020;17(12):e1003228. https://doi.org/10.1371/journal.pmed. 1003228. Cited 2020 Dec 29.

6. Al-Sumaih I, Nguyen N, Donnelly M, Johnston B, Khorgami Z, O'Neill C Ethnic disparities in use of bariatric surgery in the USA: the experience of native Americans. Obes Surg. 2020;30(7):2612-9 Available from: http:// link.springer.com/10.1007/s11695-020-04529-w. Cited 2020 Dec 20.

7. Salminen $\mathrm{P}$, Helmio M, Ovaska J, Juuti A, Leivonen M, Peromaa-Haavisto $\mathrm{P}$ et al. Effect of laparoscopic sleeve gastrectomy vs laparoscopic roux-en-y gastric bypass onweight loss at 5 years among patients with morbid obesity the SLEEVEPASS randomized clinical trial. JAMA. 2018;319(3):241-54 Available from: https://jamanetwork.com/. Cited 2020 Dec 29.

8. Cohn I, Raman J, Sui Z. Patient motivations and expectations prior to bariatric surgery: a qualitative systematic review. Obes Rev. 2019;20:1608-18 Blackwell Publishing Ltd. Available from: https://pubmed.ncbi.nlm.nih. gov/31419379/. Cited 2020 Dec 28.

9. Makarawung DJS, Monpellier VM, van den Brink F, Woertman L, Zijlstra $H$, Mink van der Molen AB, et al. Body image as a potential motivator for bariatric surgery: a case-control study. Obes Surg. 2020;30(10):3768-75 Available from: https://pubmed.ncbi.nlm.nih.gov/32451911/. Cited 2020 Dec 19.

10. Pearl RL, Wadden TA, Walton K, Allison KC, Tronieri JS, Williams NN. Health and appearance: factors motivating the decision to seek bariatric surgery. Surg Obes Relat Dis. 2019;15(4):636-42.

11. Gilmartin J, Bath-Hextall F, Maclean J, Stanton W, Soldin M. Quality of life among adults following bariatric and body contouring surgery: a systematic review. JBI Database System Rev Implement Rep. 2016;14:240-70 Available from: https://pubmed.ncbi.nlm.nih.gov/27941519/. Cited 2021 Jan 1.

12. Chandawarkar RY. Body contouring following massive weight loss resulting from bariatric surgery. Adv Psychosom Med. 2006;27:61-72 Available from: https://www.karger.com/Article/FullText/90964. Cited 2020 Dec 22.

13. Cai A, Maringa L, Hauck T, Boos AM, Schmitz M, Arkudas A, et al. Body contouring surgery improves physical activity in patients after massive weight loss - a retrospective study. Obes Surg. 2020;30(1):146-53 Available from: https://pubmed.ncbi.nlm.nih.gov/31444775/. Cited 2020 Nov 5.

14. Al-Hadithy N, Mennie J, Magos T, Stewart K. Desire for post bariatric body contouring in South East Scotland. J Plast Reconstr Aesthetic Surg. 2013;66(1):87-94.

15. Toma T, Harling L, Athanasiou T, Darzi A, Ashrafian H. Does body contouring after bariatric weight loss enhance quality of life? A systematic review of QOL studies. Obes Surg. 2018;28(10):3333-41. https://doi.org/10.1007/ s11695-018-3323-8. Cited 2021 Jan 1.

16. Vadodaria S, Trivedi D. Body contouring following massive weight loss. In: Aesthetic surgery techniques: Elsevier; 2019. p. 261-8. Available from: https://linkinghub.elsevier.com/retrieve/pii/B9780323417457000345. Cited 2020 Dec 1
17. de Vries CEE, Kalff MC, van Praag EM, Florisson JMG, Ritt MJPF, van Veen RN, et al. The influence of body contouring surgery on weight control and comorbidities in patients after bariatric surgery. Obes Surg. 2020;30(3):924-30. https://doi.org/10.1007/s11695-019-04298-1. Cited 2021 Jan 5.

18. American Society of Plastic Surgeons. 2016 plastic surgery statistics report. 2016. Available from: https://www.plasticsurgery.org/documents/ News/Statistics/2016/body-contouring-gender-confirmation-surgery2016.pdf. Cited 2020 Dec 31.

19. Monpellier VM, Antoniou EE, Mulkens S, Janssen IMC, Jansen ATM, Mink van der Molen AB. Body contouring surgery after massive weight loss. Plast Reconstr Surg. 2019;143(5):1353-60 Available from: http://journals. Iww.com/00006534-201905000-00015. Cited 2021 Jan 1.

20. American Society of Plastic Surgeons. ASPS recommended insurance coverage criteria for third-party payers: panniculectomy; 2019. p. 1-6. Available from: https://www.plasticsurgery.org/Documents/HealthPolicy/Reimbursement/insurance-2019-panniculectomy.pdf.

21. American Society of Plastic Surgeons. ASPS recommended insurance coverage criteria for third-party payers | Breast reconstruction for deformities unrelated to cancer treatment. 2018. Available from: https:// www.plasticsurgery.org/documents/Health-Policy/Reimbursement/insur ance-2018-breast-reconstruction-deformities.pdf. Cited 2021 Jan 22.

22. Munnich EL, Parente ST. Procedures take less time at ambulatory surgery centers, keeping costs down and ability to meet demand up. Health Aff. 2014;33(5):764-9 Available from: http://www.healthaffairs.org/doi/10. 1377/hlthaff.2013.1281. Cited 2020 Dec 20.

23. Winocour J, Gupta V, Roberto Ramirez J, Bruce Shack R, Grotting JC, Kye Higdon K. Abdominoplasty: risk factors, complication rates, and safety of combined procedures. In: Plastic and reconstructive surgery: Lippincott Williams and Wilkins; 2015. p. 597e-606e. Available from: http://journals. Iww.com/00006534-201511000-00009. Cited 2021 Jan 17.

24. Altieri MS, Yang J, Park J, Novikov D, Kang L, Spaniolas K, et al. Utilization of body contouring procedures following weight loss surgery: a study of 37,806 patients. Obes Surg. 2017;27(11):2981-7 Available from: https:// pubmed.ncbi.nlm.nih.gov/28600616/. Cited 2020 Dec 26.

25. Dreifuss SE, Rubin JP. Insurance coverage for massive weight loss panniculectomy: a national survey and implications for policy. Surg Obes Relat Dis. 2016;12(2):412-6 Available from: https://pubmed.ncbi.nlm.nih. gov/26707933/. Cited 2020 Dec 26.

26. Derderian SC, Patten L, Kaizer AM, Inge TH, Jenkins TM, Michalsky MP, et al. Body contouring in adolescents after bariatric surgery. Surg Obes Relat Dis. 2020;16(1):137-42 Available from: https://pubmed.ncbi.nlm.nih. gov/31668945/. Cited 2020 Dec 26.

27. Giladi AM, Aliu O, Chung KC. The effect of medicaid expansion in new york state on use of subspecialty surgical procedures by medicaid beneficiaries and the uninsured. J Am Coll Surg. 2014;218(5):889-97 Available from: https://www.ncbi.nlm.nih.gov/pmc/articles/PMC4024310/?report= abstract. Cited 2020 Dec 23.

28. Guest RA, Bourne DA, Chow I, Gusenoff JA, Peter Rubin J. The impact of massive weight loss on psychological comorbidities: a large, retrospective database review. Aesthetic Plast Surg. 2019;43(6):1570-4. https://doi. org/10.1007/s00266-019-01444-z. Cited 2021 Jan 5.

29. Orr JP, Sergesketter AR, Shammas RL, Thomas AB, Cason RW, Zhao R, et al. Assessing the relationship between anxiety and revision surgery following autologous breast reconstruction. Plast Reconstr Surg. 2019;144(1):24-33.

30. Karaca Z, McDermott KW. High-volume invasive, therapeutic ambulatory surgeries performed in hospital-owned facilities, 2016: statistical brief \#252. Healthcare Cost and Utilization Project (HCUP) statistical briefs. Agency for Healthcare Research and Quality (US); 2019. Available from: http://www.ncbi.nlm.nih.gov/pubmed/33141540. Cited 2020 Nov 24.

31. American Society of Plastic Surgeons. ASPS recommended insurance coverage criteria: surgical treatment of skin redundancy for obese and massive weight loss patients; 2017. p. 1-6. Available from: https://www. plasticsurgery.org/Documents/Health-Policy/Reimbursement/insurance2017-skin-redundancy-for-obese-and-massive-weight-loss-patients.pdf.

32. Requirements for publishing with HCUP data. Available from: https:// www.hcup-us.ahrq.gov/db/publishing.jsp. Cited 2021 Jan 20.

33. Houchens R, Elixhauser A. Final report on calculating Nationwide Inpatient Sample (NIS) variances for data years 2011 and earlier. 2015. HCUP methods series report \# 2003-02 online. 2015. Available from: http:// 
www.hcup-us.ahrq.gov/reports/methods/methods.jsp. Cited 2020 Nov 27.

34. Kitzinger HB, Abayev S, Pittermann A, Karle B, Kubiena H, Bohdjalian A et al. The prevalence of body contouring surgery after gastric bypass surgery. Obes Surg. 2012;22(1):8-12 Available from: https://link.springer. com/article/10.1007/s11695-011-0459-1. Cited 2021 Jan 24.

35. American Society of Plastic Surgeons. 2014 Plastic surgery statistics report. 2014. Available from: https://www.plasticsurgery.org/documents/ News/Statistics/2014/body-contouring-after-massive-weight-loss-2014 pdf. Cited 2021 Jan 25.

36. Ngaage LM, Elegbede A, Pace L, Rosen C, Tannouri S, Rada EM, et al. Review of insurance coverage for abdominal contouring procedures in the postbariatric population. Plast Reconstr Surg. 2020;145(2):545-54 Available from: http://journals.Iww.com/10.1097/PRS.0000000000006513. Cited 2020 Dec 20.

37. The American Society for Aesthetic Plastic Surgery. Cosmetic Surgery National Data Bank Statistics. 2016. Available from: https://www.surgery. org/sites/default/files/ASAPS-Stats2016.pdf. Cited 2021 Mar 18.

38. Sheetz KH, Woodside KJ, Shahinian VB, Dimick JB, Montgomery JR, Waits SA. Trends in bariatric surgery procedures among patients with ESKD in the United States. Clin J Am Soc Nephrol. 2019;14(8):1193-9 Available from: https://www.ncbi.nlm.nih.gov/pmc/articles/PMC6682821/. Cited 2021 Mar 18

39. Ngaage LM, Rose J, Pace L, Kambouris AR, Rada EM, Kligman MD, et al. A review of national insurance coverage of post-bariatric upper body lift. Aesthetic Plast Surg. 2019;43(5):1250-6 Available from: https://pubmed. ncbi.nlm.nih.gov/31240337/. Cited 2021 Jan 4.

\section{Publisher's Note}

Springer Nature remains neutral with regard to jurisdictional claims in published maps and institutional affiliations.

- fast, convenient online submission

- thorough peer review by experienced researchers in your field

- rapid publication on acceptance

- support for research data, including large and complex data types

- gold Open Access which fosters wider collaboration and increased citations

- maximum visibility for your research: over $100 \mathrm{M}$ website views per year

At BMC, research is always in progress.

Learn more biomedcentral.com/submissions 